\title{
Sexually transmitted infections in HIV-infected people in Switzerland: cross-sectional Study
}

Sexually transmitted infections (STI) in HIV-infected people are of increasing concern. We estimated STI prevalence and sexual healthcare seeking behaviour in 224 sexually active HIV-infected people, including men who have sex with men (MSM, $n=112$ ), heterosexual men $(n=65)$ and women $(n=47)$. Laboratory-diagnosed bacterial STI were more common in MSM (Chlamydia trachomatis 10.7\%; 95\%Cl 6.2, 18.0\%, lymphogranuloma venereum $0.9 \%$; $95 \% \mathrm{Cl} 0.1,6.2 \%$, Neisseria gonorrhoeae $2.7 \%$; $95 \% \mathrm{Cl} 0.9,8.0 \%$, syphilis seroconversion $5.4 \% ; 95 \% \mathrm{Cl} 2.0,11.3 \%$ ) than heterosexual men (gonorrhoea $1.5 \% ; 95 \% \mathrm{Cl} 0.2,10.3 \%$ ) or women (no acute infections). Combined rates of laboratory-diagnosed and self-reported bacterial STI in the year before the study were: MSM $(27.7 \%$; $95 \% \mathrm{Cl} 21.1,36.7 \%)$; heterosexual men (1.5\%; 95\% $\mathrm{Cl} 0.2,10.3 \%)$; and women $(6.4 \% ; 95 \% \mathrm{Cl} 2.1,21.0 \%)$. Antibodies to hepatitis C virus were least common in MSM. Antibodies to herpes simplex type 2 virus were least common in heterosexual men. Most MSM, but not heterosexual men or women agreed that STI testing should be offered every year. In this study, combined rates of bacterial STI in MSM were high; a regular assessment of sexual health would allow those at risk of STI to be offered testing, treatment and partner management. 
1 Katharina Sprenger, ${ }^{1}$ John Marc Evison, ${ }^{1}$ Marcel Zwahlen, ${ }^{2}$ Cedric M. Vogt ${ }^{2}$ Maria Verena Elzi, ${ }^{3}$

2 Christoph Hauser, ${ }^{1}$ Hansjakob Furrer, ${ }^{1 *}$ Nicola Low. ${ }^{2 *}$ and the Swiss HIV Cohort Study ${ }^{* *}$

3 1. Department of Infectious Diseases, Bern University Hospital and University of Bern, Bern,

4 Switzerland.

5 2. Institute of Social and Preventive Medicine, University of Bern, Bern, Switzerland.

6 3. Institute of Infectious Diseases, University of Bern, Bern, Switzerland.

$7 \quad$ * These authors contributed equally to this work.

$8{ }^{* *}$ Members of the Swiss HIV Cohort Study are listed in the appendix

9 Corresponding author: Prof. Nicola Low, Institute of Social and Preventive Medicine, University

10 of Bern, Finkenhubelweg 11, Bern, CH-3012, Switzerland. Tel: +41 3163130 92; fax: +41 31

1163135 20; email: low@ispm.unibe.ch 


\section{Introduction}

13 Sexually transmitted infections (STI) are important health risks for people living with HIV

14 infection in the era of combination antiretroviral therapy (cART) (Fakoya et al. 2007).

15 Surveillance reports of syphilis, gonorrhoea and chlamydia have risen during the 2000s,

16 particularly in men who have sex with men (MSM) (Bundesamt für Gesundheit 2013, $\underline{\text { Centers for }}$

17 Disease Control and Prevention 2014). In addition, there have been outbreaks of STI which

18 were previously rare, like lymphogranuloma venereum (LGV) (Bundesamt für Gesundheit 2005,

19 Bremer et al. 2006, Ward et al. 2007) and hepatitis C (Wandeler et al. 2012, Yaphe et al. 2012)

20 in HIV positive in MSM.

21 Regular testing for STI is recommended in some countries as part of routine follow up for all

22 people with HIV infection (California STD Controllers Association and California Coalition of

23 Local AIDS Directors 2001, Fakoya et al. 2007). But the levels of STI at which regular testing in

24 people with HIV infection is worthwhile are unclear (Rieg et al. 2008). Estimating the frequency

25 of STI can be difficult because cohort studies are challenging (Jin et al. 2007, Rieg et al. 2008)

26 and cross-sectional studies miss episodes diagnosed in different settings at different times. Jin

27 et al. tried to overcome this challenge by combining diagnoses made at yearly study visits with

28 self-reported diagnoses in the past year in a cohort of HIV negative MSM (the HIV in Men, HIM

29 study) (

30 There are no guidelines for regular STI testing in HIV-infected people in Switzerland. The Swiss

31 HIV Cohort Study (SHCS) provides regular follow up and care for about 7500 people with HIV

32 infection in Switzerland, of whom $30 \%$ are women and $35 \%$ are assumed to have acquired HIV

33 through sex between men (The Swiss HIV Cohort Study 2010). The aim of this study was to

34 inform decisions about the need for regular STI screening in HIV-infected people in Switzerland.

35 Specific objectives were to estimate the prevalence of bacterial and viral STI and patterns of 
sexual health care seeking behaviour in sexually active HIV-infected MSM, heterosexual men

37 and women.

\section{Methods}

39 We enrolled patients attending routine visits to the outpatient HIV clinic of the Bern University

40 Hospital, Switzerland from 20.05.2009 to 28.05.2010 when a clinic physician was available to

41 explain the study. Patients were eligible for inclusion if they were aged 18 years or older, had

42 confirmed HIV infection, were enrolled in the SHCS, had had sexual intercourse in the last 12

43 months and gave written consent. The doctor administered a standardised questionnaire (in

44 German, French or English) that asked about recent sexual partner history, previous STI and

45 case management. All patients underwent a standard physical examination and gave a first-

46 catch urine specimen and a blood sample. Additional specimens were taken from the throat

47 and/or rectum from patients who reported having had receptive oral or anal sex in the last year.

48 Whilst waiting for their blood test, patients were asked to complete a supplementary

49 questionnaire, which they posted into a box in the clinic or returned later by mail. There were

50 additional questions about satisfaction with management for previous STI and preferences for

51 future sexual health services. All questionnaires were labelled with only a unique identification

52 number to protect confidentiality. Additional epidemiological, patient history and cART data were

53 derived from the SHCS database. The Canton of Bern Ethical Committee approved the study

54 protocol (application number 026/09).

55 Specimens were tested in the laboratory of the University Institute of Infectious Diseases,

56 according to manufacturers' instructions. First catch urine specimens were tested by polymerase

57 chain reaction for Chlamydia trachomatis (COBAS TaqMan CT Test v2.0, Roche Diagnostics,

58 Rotkreuz, Switzerland) and Neisseria gonorrhoeae (opa-based real-time PCR assay, TIB

59 Molbiol, Berlin, Germany, on the COBAS TaqMan Analyzer, Roche Diagnostics); tests that were

60 positive for $C$. trachomatis were further examined and typed for LGV strains (ompA-based in-

61 house assay, Institute for Medical \& Molecular Diagnostics, Zürich, Switzerland). Blood was 
62 tested for herpes simplex type 2 (HSV-2) antibodies (HerpeSelect 2 ELISA IgG, Focus

63 Diagnostics, Cypress, CA, USA). Results of the most recent serological tests for syphilis,

64 hepatitis B and hepatitis C infections were obtained from the patient's SHCS clinical record.

65 Patients with a diagnosed STI received their results by telephone from the treating physician and

66 received antibiotic treatment, where appropriate, from the clinic. Uncomplicated chlamydia was

67 treated with azithromycin $1 \mathrm{~g}$ as a single dose or doxycycline $100 \mathrm{mg}$ twice daily for seven days,

68 LGV doxycycline 100mg twice daily for 21 days. Gonorrhoea was treated with ceftriaxone

69 250mg by intramuscular injection. Partner management was discussed at the same visit and

70 partners were contacted by the study doctor, with the agreement of the patient. Outcomes of

71 partner notification were asked at the next follow up visit.

72 Statistical analysis

73 Our study plan assumed that 700 HIV-infected patients would visit the outpatient clinic in one 74 year and $50 \%$ would be enrolled. Based on published studies, if the prevalence of chlamydia or 75 gonorrhoea was $10 \%(35 / 350)$, $95 \%$ confidence intervals $(95 \% \mathrm{Cl})$ would be 7.0 to $13.6 \%$ 76 (Phipps et al. 2005, Jin et al. 2007, Dang et al. 2009).

77 We conducted descriptive univariable analyses separately amongst MSM, heterosexual men 78 and women and made statistical comparisons between groups using chi-squared tests. In all 79 analyses heterosexual women and women who have sex with women were considered as a 80 single group because of the small number; no woman who has sex with women was diagnosed 81 with an STI. In each group we estimated the point prevalence of STI (with 95\% Cl) amongst 82 sexually active HIV-positive people tested using the number with a positive test result at the 83 study visit as a percentage of all participants. We used the method of Jin et al. to estimate a 84 one-year rate of diagnosed bacterial STI by adding study-diagnosed infections and self-reported 85 infections in the previous year (Jin et al. 2007). We did not do multivariable analyses because 86 the study was not designed to investigate risk factors for STI. 
101

102

103

104

105

106

107

108

109

110

111 Few participants $(11 / 224,4.9 \%)$ reported any symptoms associated with STI on the day of study 112 enrolment (see Table 2). 


\section{Bacterial Infections}

114 Sixteen men had positive test results for $N$. gonorrhoeae, C. trachomatis, or both at the study

115 visit. The prevalence of each STI (\% and 95\% CI) on the day of study enrolment is shown in

116 Table 3. Three MSM (2.7\%, 95\% Cl 0.9, 8.0\%) had gonococcal infection (two rectal, one

117 pharyngeal). One heterosexual man had pharyngeal gonorrhoea; he did not report any male

118 sexual partners and there was no confirmatory specimen for culture before treatment. All 13

119 chlamydia-infected participants were MSM; $12(10.7 \%, 95 \%$ CI 6.2, 18.0\%) had C. trachomatis

120 serovars D-K detected (five urethral, six rectal, one pharyngeal) and one had a rectal LGV

121 serovar 2b. One MSM had both rectal gonorrhoea and chlamydia. There were 45 participants

122 with positive serologic tests for syphilis with the highest estimated prevalence amongst MSM

123 ( $p<0.001)$. Amongst MSM, six $(5.4 \%, 95 \%$ Cl 2.9, 11.3\%) had newly reactive serological tests for 124 syphilis during the study period.

\section{Viral Infections}

126 Viral infections were diagnosed serologically (see Table 3); no participant with HSV-2 antibodies

127 reported genital ulceration on the day of the study visit. HSV-2 infection was common in all

128 groups of participants with more than half of MSM and women, and a third of heterosexual men

$129(p=0.028)$, having antibodies detected. In contrast, antibodies to hepatitis C were more common

130 in heterosexual men and in women than in MSM $(p<0.001)$. Amongst patients with no recent

131 history of injection drug use, more heterosexual men $(7 / 46,15.2 \%)$ and women $(6 / 43,14.0 \%)$

132 than MSM $(4 / 109,3.7 \%)$ had antibodies to hepatitis $C(p=0.038)$. Amongst those who acquired

133 HIV through injection drug use, almost all had antibodies to hepatitis C (MSM, 3/3; heterosexual

134 men 14/19; women 4/4, p=0.523). Exposure to hepatitis B virus was common in all groups. A

135 slightly higher percentage of heterosexual men (35.4\%) than MSM (25.0\%) or women $(21.3 \%)$

136 were non-immune.

\section{Cumulative Diagnoses of Acute Sexually Transmitted Infections}


138 Participants reported diagnoses, from a list of named STI, in the one year interval before the

139 study. Overall, $19 \%(21 / 112)$ of MSM and 13\% (6/47) of women reported having been diagnosed

140 with any STI. Table 4 shows the one-year cumulative rate of bacterial STI, estimated as the sum

141 of study diagnosed and self-reported (interval) infections as reported by Jin et al. (Jin et al.

142 2007). The one-year cumulative rate of any chlamydial infection at any site was $16.1 \%(95 \% \mathrm{Cl}$

$14310.3,24.1 \%)$ in MSM and 4.3\% (95\% Cl 1.1, 15.6\%) in women and of gonorrhoea the rate was

$1444.5 \%(95 \% \mathrm{Cl} 1.9,10.3 \%)$ in MSM and $1.5 \%(0.2,10.3 \%)$ in heterosexual men. Additional self-

145 reported interval STI included five MSM and one woman with genital warts, two MSM and three

146 heterosexual men with genital herpes, one woman with pubic lice and one woman with scabies.

147 STI testing and healthcare seeking behaviour

148 Amongst MSM and women, a substantial percentage reported that they had been tested for STI

149 in the 12 months before the study visit (see Table 5). Most patients who were tested reported

150 that this had been done at an HIV outpatient clinic. The most common alternative source of STI

151 care was private gynaecologists for women. A majority of participants in all groups reported that

152 they felt comfortable speaking about sexual health and STI related issues with doctors in the HIV

153 clinic. Opinions about the role of the STI clinic in offering regular STI testing differed between

154 groups, however. About three quarters of MSM agreed that STI testing should be offered

155 routinely every year. A sizeable minority of heterosexual men (10/48, 21\%) and women (12/39,

$15631 \%$ ) thought that STI tests should not be offered at HIV outpatient clinics.

\section{Discussion}

\section{Summary of main findings}

159 In this cross-sectional study of patients attending routine HIV outpatient clinics who reported

160 having had sexual intercourse in the past year, the prevalence of laboratory diagnosed bacterial

161 STI was higher in MSM than heterosexual men or women. The rate of bacterial STI in MSM and

162 women increased when self-reported infections in the year before the study visit were combined 
163 with study diagnosed infections. Antibodies to HCV were least common in MSM. Antibodies to

164 HSV-2 were least common in heterosexual men. Most MSM, but not heterosexual men or

165 women agreed that STI testing should be offered every year.

166 Strengths and weaknesses of study methods

167 Strengths of this study are that it enrolled a prospective sample of both male and female patients

168 and used standardised methods of data collection and validated laboratory tests in a single

169 centre. The number of patients assessed for eligibility matched the sample size calculation but

170 the precision of STI prevalence estimates was reduced because fewer patients than planned

171 were eligible; nearly a third of patients assessed reported that they had not had sexual

172 intercourse in the previous year. We might have missed STI diagnoses if they were, in fact,

173 sexually active but we think this unlikely, especially since so few STI were diagnosed in the

174 enrolled heterosexual men and women. The number of participants enrolled was comparable to

175 that of HIV-infected patients in other single centre studies (Bachmann et al. 2005, Stolte et al.

176 2006, Rieg et al. 2008) with a participation rate amongst eligible patients of about $50 \%$. To

177 minimise disruption to the clinic during the study period, we did not collect data about those who

178 declined participation so our interpretation assumes that non-participation was not associated

179 with the probability of having an STI diagnosis.

180 Comparison with Other Studies

181 We did not find any other prospective studies comparing the prevalence of laboratory-detected

$182 \mathrm{STI}$ in MSM, heterosexual men and women. Given the role of STI in driving HIV transmission

183 (Cohen 2012), the number of prospective studies examining STI in any groups of HIV-infected

184 people in the era of cART is modest. One global review found 37 studies of any design in any

185 population published from 2000 to 2010 (Kalichman et al. 2011). Only seven of these studies

186 examined acute bacterial STI in prospective systematic samples of HIV-infected patients in

187 Europe, Australia or North America (Whittington et al. 2002, Bachmann et al. 2005, Phipps et al.

188 2005, Stolte et al. 2006, Jin et al. 2007, Rieg et al. 2008, Dang et al. 2009) and only one 
189 included women (Phipps et al. 2005). In MSM in our study the estimated point prevalences of 190 chlamydia ( $11 \%$ any site), LGV (1\%), gonorrhoea (3\% any site), newly reactive syphilis serology

191 (5\%) were consistent with: another study in Switzerland (11\% anorectal chlamydia serovars D-K,

192 1\% LGV) (Dang et al. 2009); Australia (3\% rectal or urethral gonorrhoea, 8\% rectal or urethral

193 chlamydia) (Jin et al. 2007); and North America (14\% gonorrhoea, chlamydia or newly reactive

194 syphilis serology) (Rieg et al. 2008), (10\% gonorrhoea or chlamydia at any site) (Whittington et

195 al. 2002). Other recent studies have estimated a higher prevalence of rectal chlamydia (Stolte et

196 al. 2006). Amongst women, one study in San Francisco found no chlamydia but pharyngeal

197 gonorrhoea in 6\% (3/46) women (Phipps et al. 2005). Two studies that included men did not

198 stratify their findings by sexual orientation (Bachmann et al. 2005, Phipps et al. 2005).

199 The cumulative rate of STI in our study, combining new diagnoses and self-reported chlamydia, 200 gonorrhoea and syphilis in the preceding year $(28 \% ; 21-37 \%)$ was higher than the combined 201 rates for HIV-negative MSM estimated by Jin and colleagues (Jin et al. 2007). The prevalence of 202 STI has also been found to be higher in HIV-positive than HIV-negative MSM in Australia (Jin et 203 al. 2007), Germany (Dudareva-Vizule et al. 2013) and the USA (Whittington et al. 2002). Even if 204 some syphilis infections reported by MSM in our study were old or treated episodes (Thurnheer 205 et al. 2010), the combined rate in our study was consistent with the findings of a prospective 206 study of 212 MSM in two urban clinics in the USA who were tested at baseline, six and 12 207 months; $28 \%$ (95\% Cl 22-34\%) tested positive for chlamydia or gonorrhoea at any site or had 208 newly reactive syphilis serology (Rieg et al. 2008). Amongst women, all chlamydia infections 209 were self-reported and the combined prevalence of $4 \%$ is compatible with that of sexually active 210 women tested opportunistically in non-HIV clinic settings (Adams et al. 2004).

211 Serological evidence of HSV-2 infection was common in all groups in our study and was 212 asymptomatic in most people, as in other studies (Romanowski et al. 2009). Hepatitis C was the 213 only infection that was more common in heterosexual men and women than in MSM, even 214 amongst those who reported no recent history of injection drug use. This pattern of 
215 seroprevalence has been observed before in the SHCS as a whole (Rauch et al. 2005) and

216 probably reflects infections that resulted from past injection drug use or other parenteral

217 exposures because heterosexual transmission of hepatitis $C$ is uncommon (Bresters et al.

218 1993). The exponential increase in sexually transmitted hepatitis C infection in MSM in

219 Switzerland (Wandeler et al. 2012) began at around the time that we conducted our study. A

220 substantial minority of patients had no serologic immunity against hepatitis $B$, but we could not

221 differentiate between people who were unvaccinated, had not seroconverted, which is common

222 in people with HIV infection, or in whom titres had waned over time.

\section{Interpretation and Implications for STI Testing}

224 The point prevalences of asymptomatic STI in sexually active HIV-infected MSM in our study

225 population were similar to those in countries that recommend regular testing (California STD

226 Controllers Association and California Coalition of Local AIDS Directors 2001, Fakoya et al.

227 2007). STI testing in the routine clinic setting was feasible, most MSM in our study stated that

228 they could discuss sexual health in the HIV outpatient clinic and most would accept regular STI

229 testing. Sampling from the rectum and pharynx of MSM was important because more than half

230 of the chlamydia and gonorrhoea infections were detected at these sites (Dudareva-Vizule et al.

231 2013). STI prevalences in HIV-infected heterosexual men and women in our study were more

232 similar to those in HIV-uninfected people. Although these patient groups are less willing than

233 MSM to endorse routine STI testing, a sexual health assessment offers opportunities for offering

234 hepatitis B vaccination to non-immune individuals, early treatment for hepatitis C (Taylor et al.

235 2014) and to find out about the reproductive health needs of HIV-infected women (Fakoya et al.

236 2007).

237 A major reason for testing and treating STI in HIV-infected people is to reduce the transmissibility

238 of HIV. Diagnosis and treatment of asymptomatic bacterial STI has benefits for the individual if

239 accompanied by information about infections and their prevention for patients and their sexual

240 partners and if partners also receive treatment to prevent re-infection. Specific information for 
241 MSM about the risks of STI if they practise serosorting might be required (Marcus et al. 2011).

242 Detecting and treating asymptomatic pharyngeal and rectal gonococcal infections might help to

243 delay the spread of antimicrobial resistance, especially if antimicrobial susceptibility testing

244 allows the prescription of appropriate antibiotic regimens (Low et al. 2014). When assessing

245 sexual health in the HIV clinic, patients should be asked specifically about oral and anal sex

246 without condom use so that all potential sites of infection can be sampled.

247 Population level benefits are less clear. There are no randomised controlled trials of the effects

248 on HIV transmission of diagnosing and treating STI in HIV-positive MSM but a large impact is 249 unlikely because most new HIV infections in MSM are thought to be acquired from people who 250 are unaware that they are HIV-infected (van Sighem et al. 2012).

251 In summary, guidelines about STI testing amongst HIV-infected people should be based on local

252 knowledge about STI prevalence in women and men, and their risk of exposure. Combined

253 prevalence rates of bacterial STI in MSM in our patient population were high and further studies

254 should be done to assess generalizability to, and the need for guidance for, Switzerland as a

255 whole. A regular assessment of sexual health in HIV-infected people, including a sexual history,

256 would allow those at risk of STI to be offered testing, treatment and partner management.

\section{Acknowledgments}

258 This study is registered at ClinicalTrials.gov, study number NCT00973466.

259 Some of the clinical data for this work were collected within the Swiss HIV Cohort Study, 260 supported by the Swiss National Science Foundation (grant \# 134277). The members of the

261 Swiss HIV Cohort Study are:

262 Hubert V, Barth J, Battegay M, Bernasconi E, Böni J, Bucher HC, Burton-Jeangros C, Calmy A,

263 Cavassini M, Egger M, Elzi L, Fehr J, Fellay J, Furrer H (Chairman of the Clinical and Laboratory

264 Committee), Fux CA, Gorgievski M, Günthard H (President of the SHCS), Haerry D (deputy of 
265 “Positive Council”), Hasse B, Hirsch HH, Hösli I, Kahlert C, Kaiser L, Keiser O, Klimkait T, 266 Kouyos R, Kovari H, Ledergerber B, Martinetti G, Martinez de Tejada B, Metzner K, Müller N, 267 Nadal D, Pantaleo G, Rauch A (Chairman of the Scientific Board), Regenass S, Rickenbach M 268 (Head of Data Centre), Rudin C (Chairman of the Mother \& Child Substudy), Schöni-Affolter F, 269 Schmid P, Schultze D, Schüpbach J, Speck R, Staehelin C, Tarr P, Telenti A, Trkola A, Vernazza 270 P, Weber R, Yerly S. 
271 References

272 Adams EJ, Charlett A, Edmunds WJ and Hughes G. 2004. Chlamydia trachomatis in the United

273 Kingdom: a systematic review and analysis of prevalence studies. Sex Transm Infect 80(5): 354-

274362.

275 Bachmann LH, Grimley DM, Waithaka Y, Desmond R, Saag MS and Hook EW, 3rd. 2005.

276 Sexually transmitted disease/HIV transmission risk behaviors and sexually transmitted disease

277 prevalence among HIV-positive men receiving continuing care. Sex Transm Dis 32(1): 20-26.

278 Bremer V, Meyer T, Marcus U and Hamouda O. 2006. Lymphogranuloma venereum emerging in 279 men who have sex with men in Germany. Euro Surveill 11(9): 152-154.

280 Bresters D, Mauser-Bunschoten EP, Reesink HW, Roosendaal G, van der Poel CL, Chamuleau 281 RA, Jansen PL, Weegink CJ, Cuypers HT, Lelie PN and et al. 1993. Sexual transmission of 282 hepatitis C virus. Lancet 342(8865): 210-211.

283 Bundesamt für Gesundheit. 2005. Retrospektive Identifikation von 10 Fällen von

284 Lymphogranuloma venereum (LGV) mit Serotyp L2. Bull Bundesamt Gesundheit 48(05): 886285890.

286 Bundesamt für Gesundheit. 2013. Übertragbare Krankheiten. HIV- und STIs 2012: Trend 287 weiterhin steigend. BAG Bull. 2012(48): 910-914.

288 California STD Controllers Association and California Coalition of Local AIDS Directors. 2001.

289 Guidance for STD clinical preventive services for persons infected with HIV. Sex Transm Dis. 290 28(8): 460-463.

291 Centers for Disease Control and Prevention. (2014). Sexually Transmitted Disease Surveillance 292 2012. Retrieved 24.02.2014, from http://www.cdc.gov/std/stats. 
293 Cohen MS. 2012. Classical sexually transmitted diseases drive the spread of HIV-1: back to the 294 future. J Infect Dis 206(1): 1-2.

295 Dang T, Jaton-Ogay K, Flepp M, Kovari H, Evison JM, Fehr J, Schmid P, Boffi El Amari E, 296 Cavassini M, Odorico M, Tarr PE and Greub G. 2009. High prevalence of anorectal chlamydial 297 infection in HIV-infected men who have sex with men in Switzerland. Clin Infect Dis 49(10): $298 \quad 1532-1535$.

299 Dudareva-Vizule S, Haar K, Sailer A, Wisplinghoff H, Wisplinghoff F, Marcus U and the Psg. 300 2013. Prevalence of pharyngeal and rectal Chlamydia trachomatis and Neisseria gonorrhoeae 301 infections among men who have sex with men in Germany. Sex Transm Infect 90: 46-51.

302 Fakoya A, Lamba H, Mackie N, Nandwani R, Brown A, Bernard EJ, Gilling-Smith C, Lacey C, 303 Sherr L, Claydon P, Wallage S, Gazzard B, British HIV Association, British Association for Sexual 304 Health and HIV and Faculty of Family Planning \& Reproductive Health Care. 20072007 UK 305 guidelines for the management of sexual and reproductive health (SRH) of people living with HIV 306 infection. http://www.bashh.org/documents/91/91.pdf.

307 Jin F, Prestage GP, Mao L, Kippax SC, Pell CM, Donovan B, Cunningham PH, Templeton DJ, 308 Kaldor JM and Grulich AE. 2007. Incidence and risk factors for urethral and anal gonorrhoea and 309 chlamydia in a cohort of HIV-negative homosexual men: the Health in Men Study. Sexually 310 Transmitted Infections 83(2): 113-119.

311 Jin F, Prestage GP, Zablotska I, Rawstorne P, Kippax SC, Donovan B, Cunningham PH, 312 Templeton DJ, Kaldor JM and Grulich AE. 2007. High rates of sexually transmitted infections in 313 HIV positive homosexual men: data from two community based cohorts. Sex Transm Infect 314 83(5): 397-399. 
315 Kalichman SC, Pellowski J and Turner C. 2011. Prevalence of sexually transmitted co-infections

316 in people living with HIVIAIDS: systematic review with implications for using HIV treatments for

317 prevention. Sex Transm Infect 87(3): 183-190.

318 Low N, Unemo M, Skov Jensen J, Breuer J and Stephenson JM. 2014. Molecular diagnostics for 319 gonorrhoea: implications for antimicrobial resistance and the threat of untreatable gonorrhoea.

320 PLoS Med 11(2): e1001598.

321 Marcus U, Schmidt AJ and Hamouda O. 2011. HIV serosorting among HIV-positive men who

322 have sex with men is associated with increased self-reported incidence of bacterial sexually

323 transmissible infections. Sexual Health 8(2): 184-193.

324 Phipps W, Stanley H, Kohn R, Stansell J and Klausner JD. 2005. Syphilis, chlamydia, and

325 gonorrhea screening in HIV-infected patients in primary care, San Francisco, California, 2003.

326 AIDS Patient Care STDS 19(8): 495-498.

327 Rauch A, Rickenbach M, Weber R, Hirschel B, Tarr PE, Bucher HC, Vernazza P, Bernasconi E,

328 Zinkernagel AS, Evison J, Furrer H and Study SHC. 2005. Unsafe Sex and Increased Incidence

329 of Hepatitis C Virus Infection among HIV-Infected Men Who Have Sex with Men: The Swiss HIV

330 Cohort Study. Clin Infect Dis 41(3): 395-402.

331 Rieg G, Lewis RJ, Miller LG, Witt MD, Guerrero M and Daar ES. 2008. Asymptomatic sexually

332 transmitted infections in HIV-infected men who have sex with men: prevalence, incidence,

333 predictors, and screening strategies. AIDS Patient Care STDS 22(12): 947-954.

334 Romanowski B, Myziuk LN, Walmsley SL, Trottier S, Singh AE, Houston S, Joffe M and Chiu I.

335 2009. Seroprevalence and risk factors for herpes simplex virus infection in a population of HIV-

336 infected patients in Canada. Sex Transm Dis 36(3): 165-169. 
337 Stolte IG, de Wit JB, Kolader M, Fennema H, Coutinho RA and Dukers NH. 2006. Association

338 between 'safer sex fatigue' and rectal gonorrhea is mediated by unsafe sex with casual partners

339 among HIV-positive homosexual men. Sex Transm Dis 33(4): 201-208.

340 Taylor LE, Foont JA, DeLong AK, Wurcel A, Linas BP, Chapman S, Maynard MA, Cu-Uvin S and 341 Mayer KH. 2014. The Spectrum of Undiagnosed Hepatitis C Virus Infection in a US HIV Clinic. 342 AIDS Patient Care STDS 28(1): 4-9.

343 The Swiss HIV Cohort Study. 2010. Cohort Profile: The Swiss HIV Cohort Study. Int J Epidemiol $344 \quad 39(5): 1179-1189$.

345 Thurnheer MC, Weber R, Toutous-Trellu L, Cavassini M, Elzi L, Schmid P, Bernasconi E, 346 Christen AB, Zwahlen M, Furrer H and Swiss HIVCS. 2010. Occurrence, risk factors, diagnosis 347 and treatment of syphilis in the prospective observational Swiss HIV Cohort Study. AIDS 24(12): 348 1907-1916.

349 van Sighem A, Vidondo B, Glass TR, Bucher HC, Vernazza P, Gebhardt M, de Wolf F, 350 Derendinger S, Jeannin A, Bezemer D, Fraser C and Low N. 2012. Resurgence of HIV infection 351 among men who have sex with men in Switzerland: mathematical modelling study. PloS One 352 7(9): e44819.

353 Wandeler G, Gsponer T, Bregenzer A, Günthard HF, Clerc O, Calmy A, Stöckle M, Bernasconi E, 354 Furrer H, Rauch A and Study tSHC. 2012. Hepatitis C Virus Infections in the Swiss HIV Cohort 355 Study: A Rapidly Evolving Epidemic. Clin Infect Dis 55(10): 1408-1416.

356 Ward H, Martin I, Macdonald N, Alexander S, Simms I, Fenton K, French P, Dean G and Ison C. 357 2007. Lymphogranuloma venereum in the United kingdom. Clin.Infect Dis. 44(1): 26-32. 
358 Whittington WL, Collis T, Dithmer-Schreck D, Handsfield HH, Shalit P, Wood RW, Holmes KK

359 and Celum CL. 2002. Sexually transmitted diseases and human immunodeficiency virus-

360 discordant partnerships among men who have sex with men. Clin Infect Dis 35(8): 1010-1017.

361 Yaphe S, Bozinoff N, Kyle R, Shivkumar S, Pai NP and Klein M. 2012. Incidence of acute

362 hepatitis $\mathrm{C}$ virus infection among men who have sex with men with and without HIV infection: a

363 systematic review. Sex Transm Infect 88(7): 558-564. 


\section{Figure 1}

Flow chart of included and excluded patients 


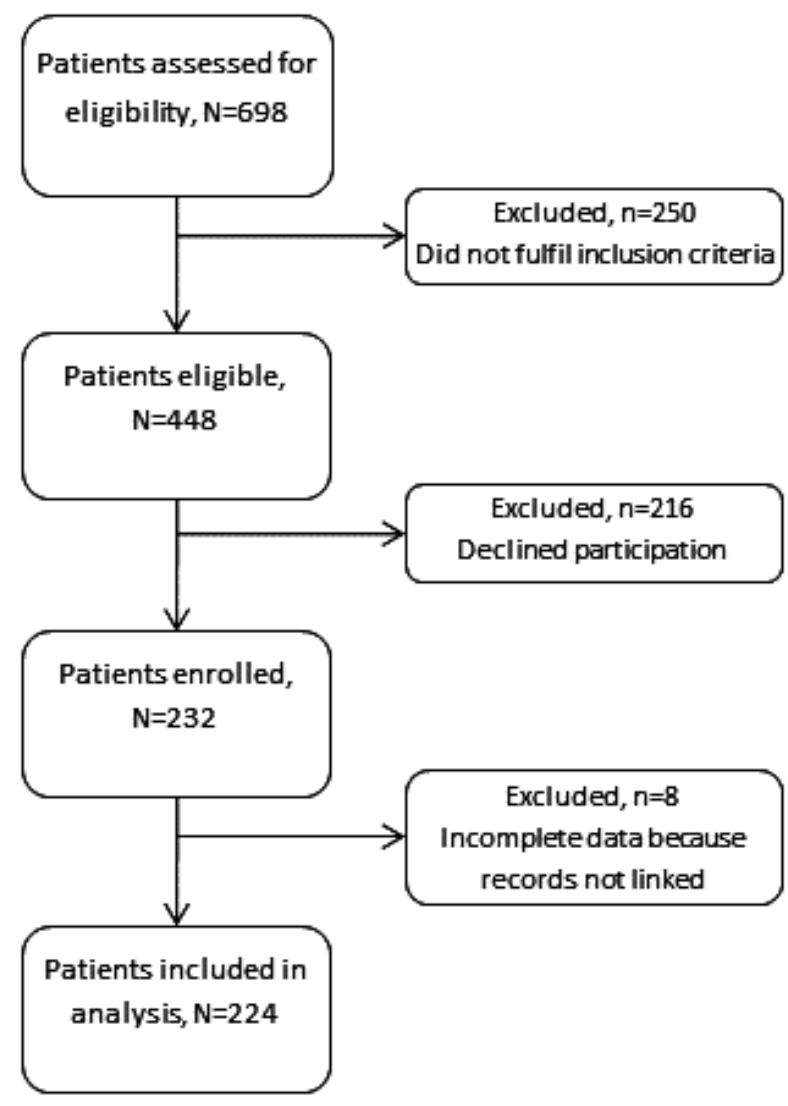




\section{Table 1 (on next page)}

Characteristics of study participants at enrolment $(\mathrm{N}=224)$

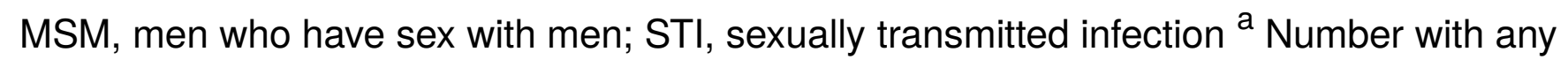
casual partners is sum of those with only casual and those with both casual and regular partners ${ }^{b}$ Number with any regular partners is sum of those with only regular and those with both casual and regular partners 


\begin{tabular}{llcc}
\hline Characteristic & & $N$ & $(\%)$ \\
Sex, sexual orientation & Men who have sex with men & 112 & $(50.0)$ \\
& Heterosexual men & 65 & $(29.1)$ \\
& Heterosexual women & 44 & $(19.6)$ \\
& Women who have sex with women & 3 & $(1.3)$ \\
Route of HIV acquisition & Sex between men & 108 & $(48.2)$ \\
& Heterosexual sex & 77 & $(34.4)$ \\
& Injection drug use & 26 & $(11.6)$ \\
& Other or unknown & 13 & $(5.8)$ \\
Country of birth & Switzerland & 114 & $(50.9)$ \\
& Other & 38 & $(17.0)$ \\
Age in years, mean (standard deviation) & 72 & $(32.1)$ \\
CD4 count on day of visit, cells/pl, mean (standard deviation) & $44.4(9.1)$ & na \\
Viral load $<40$ copies/mL & Yes, received antiretroviral therapy & $525.9(280)$ & na \\
& Yes, never received antiretroviral therapy & 154 & $(68.8)$ \\
& No, ever received antiretroviral therapy & 2 & $(0.9)$ \\
& No, never received antiretroviral therapy & 16 & $(7.1)$ \\
& Missing & 37 & $(16.5)$ \\
\hline
\end{tabular}




\section{Table 2 (on next page)}

Sexual behaviours reported by patient to physician $(\mathrm{N}=224)$

MSM, men who have sex with men; STI, sexually transmitted infection ${ }^{2}$ Number with any casual partners is sum of those with only casual and those with both casual and regular partners ${ }^{b}$ Number with any regular partners is sum of those with only regular and those with both casual and regular partners 


\begin{tabular}{|c|c|c|c|c|c|c|c|}
\hline \multirow[b]{2}{*}{ Symptoms and sexual partnerships } & \multicolumn{2}{|c|}{$M S M$} & \multicolumn{2}{|c|}{$\begin{array}{c}\text { Heterosexual } \\
\text { Men }\end{array}$} & \multicolumn{2}{|c|}{ Women } & \multirow[t]{2}{*}{$P$ Value } \\
\hline & $\mathrm{N}=112$ & $(\%)$ & $\mathrm{N}=65$ & $e_{(\%)}$ & $\mathrm{N}=47$ & $(\%)$ & \\
\hline \multicolumn{8}{|l|}{ Any STI symptoms on day of visit } \\
\hline Yes & 7 & (6.4) & 3 & (4.6) & 1 & $(2.1)$ & 0.562 \\
\hline No & 102 & $(91.1)$ & 62 & $(95.4)$ & 45 & (97.8) & \\
\hline Not reported & 3 & $(2.7)$ & 0 & (0) & 1 & (2.1) & \\
\hline \multicolumn{8}{|l|}{ Total number of sexual partners in past year } \\
\hline 1 & 34 & $(30.4)$ & 51 & (78.5) & 42 & (89.4) & $<0.001$ \\
\hline $2-4$ & 23 & $(20.5)$ & 11 & $(16.9)$ & 3 & $(6.4)$ & \\
\hline 5 & 55 & $(49.1)$ & 3 & (4.6) & 2 & $(4.3)$ & \\
\hline \multicolumn{8}{|l|}{ Sexual partnership type(s) } \\
\hline Casual partners only & 44 & $(39.3)$ & 14 & $(21.5)$ & 2 & $(4.3)$ & $<0.001$ \\
\hline Both regular and casual partners & 34 & $(30.4)$ & 3 & (4.6) & 4 & $(8.5)$ & \\
\hline Regular partners only & 34 & $(30.4)$ & 48 & $(73.8)$ & 41 & $(87.2)$ & \\
\hline Sexual practices, any casual partners ${ }^{a}$ & $N=78$ & $(\%)$ & $\mathrm{N}=17$ & $(\%)$ & $\mathrm{N}=6$ & $(\%)$ & \\
\hline \multicolumn{8}{|l|}{ Receptive anal intercourse } \\
\hline Yes, consistent condom use & 46 & $(59.0)$ & 0 & (0) & 3 & $(50.0)$ & $<0.001$ \\
\hline Yes, no consistent condom use & 14 & $(18.0)$ & 0 & (0) & 0 & (0) & \\
\hline No or not reported & 18 & $(23.0)$ & 17 & (100) & 3 & $(50.0)$ & \\
\hline \multicolumn{8}{|l|}{ Insertive anal intercourse } \\
\hline Yes, consistent condom use & 37 & $(47.4)$ & 1 & (5.9) & 0 & (0) & $<0.001$ \\
\hline Yes, no consistent condom use & 17 & $(21.8)$ & 1 & $(5.9)$ & 0 & (0) & \\
\hline No or not reported & 24 & $(30.8)$ & 15 & $(88.2)$ & 6 & $(100)$ & \\
\hline \multicolumn{8}{|l|}{ Vaginal intercourse } \\
\hline Yes, consistent condom use & 4 & $(5.1)$ & 14 & $(82.4)$ & 2 & $(33.3)$ & $<0.001$ \\
\hline Yes, no consistent condom use & 0 & (0) & 2 & $(11.8)$ & 1 & 16.7) & \\
\hline No or not reported & 74 & $(94.9)$ & 1 & $(5.9)$ & 3 & $(50.0)$ & \\
\hline Sexual practices, any regular partners ${ }^{\mathrm{b}}$ & $\mathrm{N}=68$ & $(\%)$ & $N=51$ & $(\%)$ & $\mathrm{N}=45$ & $(\%)$ & \\
\hline \multicolumn{8}{|l|}{ Receptive anal intercourse } \\
\hline Yes, consistent condom use & 37 & $(54.4)$ & 0 & (0) & 1 & $(2.2)$ & $<0.001$ \\
\hline Yes, no consistent condom use & 14 & $(20.6)$ & 0 & (0) & 0 & (0) & \\
\hline No or not reported & 17 & $(25.0)$ & 51 & $(100)$ & 44 & $(97.8)$ & \\
\hline \multicolumn{8}{|l|}{ Insertive anal intercourse } \\
\hline Yes, consistent condom use & 31 & $(45.6)$ & 0 & (0) & 0 & (0) & $<0.001$ \\
\hline Yes, no consistent condom use & 8 & $(11.8)$ & 1 & $(2.0)$ & 0 & (0) & \\
\hline No or not reported & 29 & $(42.7)$ & 50 & $(98.0)$ & 45 & $(100)$ & \\
\hline \multicolumn{8}{|l|}{ Vaginal intercourse } \\
\hline Yes, consistent condom use & 3 & $(4.4)$ & 36 & $(70.6)$ & 24 & $(53.3)$ & $<0.001$ \\
\hline Yes, no consistent condom use & 1 & $(1.5)$ & 14 & $(27.5)$ & 17 & $(37.8)$ & \\
\hline No or not reported & 64 & $(94.1)$ & 1 & $(1.9)$ & 4 & $(8.9)$ & \\
\hline
\end{tabular}




\section{Table 3 (on next page)}

Laboratory diagnosed sexually transmitted infections $(n=224)$

Numbers in italics show the distribution of infections by site ${ }^{a}$ One MSM had both chlamydia and gonorrhoea ${ }^{b}$ Serologic tests done at baseline (Treponema pallidum haemagglutination assay, TPHA) and yearly thereafter, with follow up tests done as clinically indicated ${ }^{\mathrm{C}}$ No result available for 11/112 MSM, 3/65 heterosexual men, $1 / 47$ women ${ }^{d}$ No result available for 9/112 MSM, 2/65 heterosexual men, 1/47 women 


\begin{tabular}{|c|c|c|c|c|c|c|c|}
\hline \multirow[t]{2}{*}{ Infection } & \multicolumn{2}{|c|}{$M S M, N=112$} & \multicolumn{2}{|c|}{$\begin{array}{l}\text { Heterosexual men, } \\
\qquad N=65\end{array}$} & \multicolumn{2}{|c|}{ Women, $N=47$} & \multirow[t]{2}{*}{$P$ value } \\
\hline & $\mathrm{n}^{\mathrm{a}}$ & $\%(95 \% \mathrm{Cl})$ & $\mathrm{n}$ & $\%(95 \% \mathrm{Cl})$ & $\mathrm{n}$ & $\%(95 \% \mathrm{Cl})$ & \\
\hline Chlamydia, serovars D-K & 12 & $10.7(6.2,18.0)$ & 0 & .. & 0 & .. & 0.002 \\
\hline Urethral & 5 & & 0 & & 0 & & \\
\hline Rectal & 6 & & 0 & & 0 & & \\
\hline Pharyngeal & 1 & & 0 & & 0 & & \\
\hline LGV, rectal & 1 & $0.9(0.1,6.2)$ & 0 & .. & 0 & .. & 0.606 \\
\hline Gonorrhoea & 3 & $2.7(0.9,8.0)$ & 1 & $1.5(0.2,10.3)$ & 0 & .. & 0.499 \\
\hline Urethral & 0 & & 0 & & 0 & & \\
\hline Rectal & 2 & & 0 & & 0 & & \\
\hline Pharyngeal & 1 & & 1 & & 0 & & \\
\hline \multicolumn{8}{|l|}{ Syphilis $^{b}$} \\
\hline $\begin{array}{l}\text { Any positive serologic } \\
\text { test }\end{array}$ & 39 & $\begin{array}{c}34.8(26.5 \\
44.2)\end{array}$ & 1 & $1.5(0.2,10.3)$ & 5 & $10.6(4.5,23.3)$ & $<0.001$ \\
\hline $\begin{array}{l}\text { Seroconversion during } \\
\text { study period }\end{array}$ & 6 & $5.4(2.0,11.3)$ & 0 & .. & 0 & .. & 0.046 \\
\hline HSV-2 & 58 & $\begin{array}{c}51.8(39.1 \\
57.5)\end{array}$ & 23 & $\begin{array}{c}35.4(24.7 \\
\quad 47.8)\end{array}$ & 28 & $\begin{array}{c}59.6(45.0 \\
72.6)\end{array}$ & 0.028 \\
\hline $\begin{array}{l}\text { Hepatitis C, antibody } \\
\text { positive }^{c}\end{array}$ & 7 & $6.3(3.0,12.6)$ & 21 & $\begin{array}{l}32.3(22.0 \\
\quad 44.6)\end{array}$ & 10 & $\begin{array}{c}21.3(11.8 \\
35.3)\end{array}$ & $<0.001$ \\
\hline Hepatitis $B^{d}$ & & & & & & & 0.117 \\
\hline sAg or eAg positive & 2 & $1.8(0.4,6.9)$ & 6 & $9.2(4.2,19.2)$ & 2 & $4.3(1.1,15.6)$ & \\
\hline Core antibody positive & 46 & $\begin{array}{c}41.1(32.3 \\
50.5)\end{array}$ & 19 & $\begin{array}{l}29.2(19.4 \\
\quad 41.5)\end{array}$ & 21 & $\begin{array}{c}44.7(31.2 \\
59.1)\end{array}$ & \\
\hline $\begin{array}{l}\text { Surface antibody } \\
\text { positive, core antibody } \\
\text { negative }\end{array}$ & 27 & $\begin{array}{l}24.1(17.0 \\
33.0)\end{array}$ & 15 & $\begin{array}{l}23.1(14.4 \\
34.9)\end{array}$ & 13 & $\begin{array}{c}27.7(16.7 \\
42.1)\end{array}$ & \\
\hline Non-immune & 28 & $\begin{array}{c}25.0(17.8 \\
33.9) \\
\end{array}$ & 23 & $\begin{array}{c}35.4(24.7 \\
47.8)\end{array}$ & 10 & $\begin{array}{c}21.3(11.8, \\
35.3)\end{array}$ & \\
\hline
\end{tabular}




\section{Table 4 (on next page)}

Cumulative one year rate of laboratory confirmed and self-reported sexually transmitted infection diagnoses

LGV, lymphogranuloma venereum; STI, sexually transmitted infection ${ }^{2}$ Numbers of patients with infections diagnosed at study visit taken from Table $3{ }^{\mathrm{b}}{ }^{\mathrm{T}}$ The question asked about chlamydia infection and did not distinguish between urogenital and LGV serovars or by clinical site of infection, so these have been grouped together; ${ }^{c}$ Study diagnoses include only patients with serological evidence of new infection. Interval diagnoses include all those who said they had been diagnosed with syphilis in the previous year. Not asked if new or old diagnosis; ${ }^{d}$ Total is the number of individual patients with either a study visit or interval diagnosis of any chlamydial infection, gonorrhoea or syphilis. 


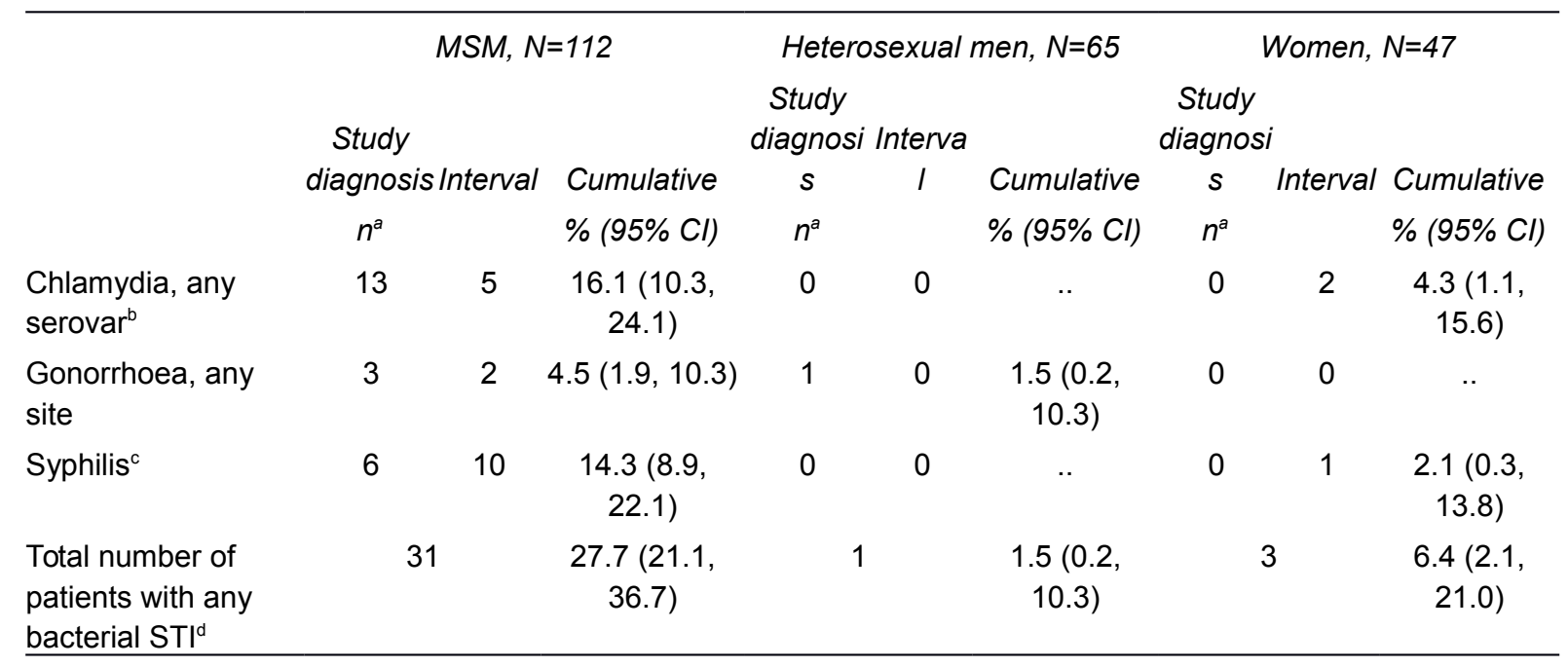




\section{Table 5 (on next page)}

Previous sexually transmitted infection testing and management, reported by patients $(n=182)$

MSM, men who have sex with men; STI, sexually transmitted infection ${ }^{\mathrm{a}}$ Not all participants returned a questionnaire; no responses from 17/112 MSM, 17/65 heterosexual men, 8/47 women. 


\begin{tabular}{|c|c|c|c|c|c|c|c|}
\hline & \multicolumn{2}{|c|}{$\begin{array}{r}M S M,^{a} \\
N=95\end{array}$} & \multicolumn{2}{|c|}{$\begin{array}{l}\text { Heterosexual } \\
m e n,{ }^{a} N=48\end{array}$} & \multicolumn{2}{|c|}{$\begin{array}{c}\text { Women, }{ }^{a} \\
N=39\end{array}$} & \multirow[t]{2}{*}{$\begin{array}{c}P \\
\text { value }\end{array}$} \\
\hline & $n$ & (\%) & $n$ & $(\%)$ & $n$ & $(\%)$ & \\
\hline $\begin{array}{l}\text { Have you been tested for any STI in the last } 12 \\
\text { months? }\end{array}$ & & & & & & & 0.015 \\
\hline Yes, tested positive for any STI & 21 & (22.1) & 4 & (8.3) & 6 & $(15.4)$ & \\
\hline Yes, tested negative for all & 29 & $(30.5)$ & 6 & (12.5) & 7 & $(18.0)$ & \\
\hline No, not tested & 39 & $(41.1)$ & 33 & $(68.8)$ & 20 & $(51.3)$ & \\
\hline Not known & 6 & $(6.3)$ & 5 & $(10.4)$ & 6 & $(15.4)$ & \\
\hline Where have tests for STI been done? & & & & & & & 0.006 \\
\hline HIV outpatient clinic & 45 & $(47.4)$ & 8 & $(16.7)$ & 9 & $(23.1)$ & \\
\hline STI specialist & 0 & (0) & 1 & $(2.1)$ & 0 & (0) & \\
\hline General practitioner & 4 & $(4.2)$ & 1 & $(2.1)$ & 0 & (0) & \\
\hline Gynaecologist & 1 & $(1.1)$ & 0 & (0) & 4 & $(10.3)$ & \\
\hline Not tested or not known & 45 & $(47.4)$ & 38 & $(79.2)$ & 26 & $(66.7)$ & \\
\hline $\begin{array}{l}\text { Can you talk about sexual health and STI at the HIV } \\
\text { clinic? }\end{array}$ & & & & & & & 0.336 \\
\hline Yes & 68 & $(71.6)$ & 31 & (64.6) & 23 & $(59.0)$ & \\
\hline No & 23 & $(24.2)$ & 15 & $(31.3)$ & 14 & $(35.9)$ & \\
\hline No response & 4 & $(4.2)$ & 2 & $(4.2)$ & 2 & $(5.1)$ & \\
\hline $\begin{array}{l}\text { Should STI testing be done at the HIV outpatient } \\
\text { clinic? }\end{array}$ & & & & & & & $<0.001$ \\
\hline Yes, regularly & 69 & $(72.6)$ & 17 & $(35.4)$ & 16 & $(41.0)$ & \\
\hline Yes, but only if I have symptoms & 13 & $(13.7)$ & 10 & $(20.8)$ & 3 & $(7.7)$ & \\
\hline Yes, but only if I have been at risk & 5 & $(5.3)$ & 9 & $(18.8)$ & 7 & $(18.0)$ & \\
\hline No & 6 & $(6.3)$ & 10 & $(20.8)$ & 12 & $(30.8)$ & \\
\hline No response & 2 & $(2.1)$ & 2 & $(4.2)$ & 1 & $(2.6)$ & \\
\hline
\end{tabular}

